visited and of the statistics which were obtained. The statistical portion of the report would lay no claim to completeness. Similar but more extensive information is included in the very useful appendices to the Survey of the Textile Industries published by Sir Arthur Balfour's Committee on Industry and Trade. Such statistical reports, in view of the somewhat meagre information which has hitherto been available, are of considerable value to the industry itself.

The report makes special reference to the work on the constitution of cellulose upon which Dr. R. O. Herzog and his colleagues are engaged at the KaiserWilhelm-Institut für Faserstoffchemie, Berlin-Dahlem. Their work, which is based on the crystalloid theory of the structure of the wool fibre, has involved the considerable use of X-ray methods. The crystalloid theory of the wool fibre is not, of course, new. It does, however, provide a useful application of the relatively new conception of colloids of definite volume. Dr. Herzog gave a complete exposition of this work and of his own investigations in this connexion, at the spring conference of the Textile Institute, which was held in Cologne. A full account of the work appears in the Journal of the Textile Institute. Amongst other important investigations upon which Dr. Herzog is engaged, is the examination of the elastic properties of fibres. This work is of obvious importance to wool textile technologists.

Dr. Paul Krais, who directs the Deutsches Forschungsinstitut für Textilindustrie at Dresden, has devised an apparatus by means of which the evenness of stretch of fibres is being automatically recorded, apparently with rapidity and precision. He is also experimenting with a machine designed to measure felting properties. He appears to be able to secure that standard squares of cloth woven in different manner are subjected to uniform felting action under standardised conditions.

The portion of the report devoted to the activities at the Institut für Tierzucht at Hanover, and at Verviers and Roubaix, is likely to be of special interest to those actually engaged in the industry. At Hanover some three hundred students are being trained in animal husbandry under Dr. H. C. C. Kronacher, who is, of course, well known for his work on sheep breeding problems. At Roubaix and Tour. coing special attention is being given to the classing and sorting of wools. In its reference to this matter, the report contains the statement that the initial operation of wool sorting in England differs fundamentally in principle from that performed in France. In particular it asserts that " while in Bradford wool is sorted according to length of fibre, in Roubaix and Tourcoing it is sorted according to fineness." This statement appears to be misleading, as it does not represent entirely the current trade practice in Bradford wool-sorting warehouses.

The Association intends to continue the survey which it has initiated through these continental visits, by sending a member of its staff to Australia, New Zealand, South Africa, and Canada. The cost of this projected survey is to be met by the Empire Marketing Board, which has made a special grant of $£ 2000$ a year for two years to the Association. The survey is to include a study of sheep populations, of systems of management and marketing, of the relationship of wool to mutton production, of the distribution of breeds and types, and of the effect of climatic eonditions and nutrition. The analysis of the various wools from the different colonies will form a complementary piece of work which will be undertaken in the laboratories of the Association.

\title{
The Fossil Redwoods of the Manchurian Coal Deposits.
}

IN recent issues of Science News-letter, issued by 1 Science Service of Washington, D.C., Dr. R. W. Chaney discusses his discoveries of fossil redwood remains in the Manchurian coal deposits, and describes some investigations carried out in the arid region of the Gobi in Mongolia. It will be remem. bered that it was in this region that the expeditions of the American Museum of Natural History discovered the famous dinosaur eggs.

Dr. Chaney's investigations afford some light on the botanical and climatological conditions of the Gobi in geological times. He has been unable to find that the Gobi region has ever supported a rich forest of the Manchurian redwood type, or indeed any extensive forests at all. During the Cretaceous period, which was the time of the dinosaurs, the dominant trees were Araucarias, modern forms of which are known in cultivation as the monkey-puzzle tree, Norfolk Island pine, and by other names. They are now native only to lands in the southern hemisphere, especially in South America. The living Araucaria species all prefer cool, rather dry habitats, and independent geological evidence connected with the dinosaurs indicates that the Mongolian species of these great lizards were dry land, cool climate animals. Thus we have two lines of evidence that the Gobi of two million years ago was more or less like the Gobi of to-day; not so dry, perhaps, but certainly not a moist country, and subject to a rather cool climate.

Other fossils of a later date, the Tertiary, when the dinosaurs had become extinct, show that the Gobi had still much the same kind of climate. At present there are no trees at all in the Gobi proper, but in the canyons of the Altai Mountains, which extend out into it, there are numerous cotton-woods and shrubby junipers. These species, growing under conditions of low rainfall which make life possible for most woody growth, may be supposed to reflect the environment in Mongolia during the Tertiary, a suggestion which is amply supported by the associated fossil animals. These are almost entirely of types found in the plains, including none of the forest animals which should be preserved in the rocks had there been widespread forests in Mongolia during that period.

From the point of view of former tree distribution in Manchuria the work of Dr. Chaney unfolds a fascinating page. The forests that grow in northern California to-day, it is said, are so much like those Manchurian forests of millions of years ago that only an expert professional botanist could tell them apart. The track of the ' march of the redwoods,' as the author expresses it, was found associated with the great Manchurian coal deposits, some of which are already being worked. Mixed with the fossil records of the redwoods, though in far smaller amounts, were alder, oak, maple, and fern.

Dr. Chaney postulates the question: What was their line of march? Did they originate in the Old World and cross over to the New by way of the Bering Straits region, as the human race is assumed to have done? Or did they evolve first in America and go west until they reached Asia? He wisely refrains from giving an answer at present, until further research work has been undertaken in connexion with this absorbing problem. He refers to a hint, from the distribution map of the finds of redwood fossils, of a possible third alternative. These finds are spotted away up in the Arctic: in Spitsbergen, on the west coast of Greenland, on the waste tundras of northern Canada, and one find far up amongst those desolate islands north of Baffin Land 
where Peary used to go when he turned his face towards the then unconquered Pole. Geologists have good evidence that these icy lands once had temperate climates, with at times even sub-tropic conditions. "May it not be that the nursery of the redwoods was in a lost polar paradise, now buried under the groaning glaciers of Greenland, or perhaps even sunk beneath the Aretic Ocean?"

Some idea of the elimate of Manchuria of this geological period is obtained. The redwood fossils found were like the Californian coast redwoods, rather than the 'big trees' of the more inland mountains. The present Californian coastal forest enjoys an equable climate, without freezing temperatures, a rather humid atmosphere, and a rainfall of from forty to fifty inches, distributed fairly evenly throughout the year. This is a much milder climate than Manchuria has had during historic times, and probably than it has had since the Pleistocene, or glacial period. The existing Manchurian forests consist of oaks, maples, elms, and other species, but nothing resembling the redwood forests.

This investigation has opened up a most fascinating chapter in former tree distribution, and the results of Dr. Chaney's further researches will be awaited with interest.

\section{Electrical Heating of Metals.}

THE increasing interest which is being taken in electrical heating in connexion with heattreatment of metals is exemplified by a pamphlet received from the Integra Co., Ltd., 183 Broad Street, Birmingham, as agents for the Leeds and Northrop Co., of Philadelphia, Pa., U.S.A. The necessity for the accurate heat treatment of expensive engineering steel parts is emphasised, the advantages of electric heating for this purpose, coupled with the exact control which is thus rendered possible, being probably ideal. The specific advantages possessed by electrical heating for hardening tools, dies, and similar articles are, in many cases, an increase of life due to accurate control of the time of heating and of the quenching temperature, reduction to a minimum of tools broken in the hardening and in distortion, and the possibility of treating the steel under conditions which do not lead to decarburisation. The equipment is flexible in the sense that it can be added to from time to time, and possesses the very marked industrial advantage that, since little heat escapes from the furnace into the room, the hardening plant can be put in the "line of production." The working conditions can also be made very much more pleasant than is often the case with other methods of heating. Electrical heating lends itself to accurate pyrometric, and often automatic, control, with a decrease in the amount of skilled labour required.
These advantages are possessed by Messrs. Leeds and Northrop's apparatus, but are, of course, inherent in electrical heating generally, when the apparatus is well designed, and are not possessed uniquely by the plant under review.

A pamphlet, also issued by the Leeds and Northrop Co., dealing with the electric furnace tempering of steel, describes their ' homo ' furnace, which is suitable for the tempering of hardened steel parts. The outstanding feature of this apparatus is the reversible air current which is passed through the charge during the whole time that it is being heated up to the tempering temperature. The steel to be treated is contained in a basket which is lowered inside a cylindrical wall that forms the inner surface of the furnace. The basket is open at the top, and is closed at the lower end by a heavy grid. Below the basket is a fan driven by an external motor that reverses automatically, driving the heatedrair alternately up through the charge and down through an angular space between the basket and the wall of the furnace, and then in the opposite direction. Between the inner wall of the furnace, which closely surrounds the basket and the heavily insulated outer wall, is this air space in which the heating coils of nickel chromium wire are situated. A very uniform heating is claimed for the method, together with the impossibility of over-heating the charge in the basket.

\section{The Relationship of Crop Yield and Weather.}

IN the Monthly Weather Review for February last, Messrs. J. B. Kincer and W. A. Mattice give examples of the practical application of a method of showing the relationship between the yield of a crop and various meteorological factors affecting it during its period of growth. The figures relate to wheat in North Dakota and Ohio. The method may be described as a modification of ordinary partial correlation suitable to cases where so many factors are involved that full treatment by the ordinary methods of partial correlation. would involve an excessive amount of computation. The final result takes the form of a regression equation between the yield $x$ and a limited number of such weather factors as are found to have significant simple correlation with $x$. In each of the examples given these factors combined are equivalent to a single meteorological variable giving a correlation coefficient of 0.93 with $x$.

The method of calculation is as follows :

(1) Correlation coefficients are worked out between each weather factor and $x$. These are lettered in the order of their absolute magnitude, $a$ being the largest.

(2) The partial correlation coefficient (or 'multiple coefficient' as it is called here) between $a$ and $x$, eliminating the influence of $b$, is worked out, and similarly for $c, d$, e etc.

(3) From the highest of these partial correlation coefficients the value of $x$ for each year is computed from the appropriate regression equation.

(4) The quantity so obtained is designated $a$, and if we suppose that $e$ is the weather factor that was eliminated in the partial regression equation, then $e$ and $a$ are not considered any further, the cycle of operations being repeated with $a_{2}$ in place of $a$, and the remaining factors $b, c, d, f$, etc.

(5) A fresh set of calculated values of $x$, arrived at from $a_{1}$ and another weather factor, give the values of the new quantity $a_{2}$, and, as before, another weather factor (c, say) drops out of the cycle, leaving $a_{2}, b$, $d, f$, etc.

(6) Up to a certain point the value of the highest partial correlation coefficient increases with each application of the process. When this point is reached a partial regression equation is formed involving the various factors used in the partial regression equations for $a_{1}, a_{2}, a_{3}$, etc., and the remaining factors are rejected.

The coefficients found indicate that about 86 per cent of the standard deviation of the yield is accounted for by the weather factors, which referred to temperature, sunshine, rainfall, and humidity, for the period April to July in the case of North Dakota, and late April to late September for Ohio. It is evident that the method may be applied to any variables, and could be used for forecasting. $\quad$ E. V. N. 